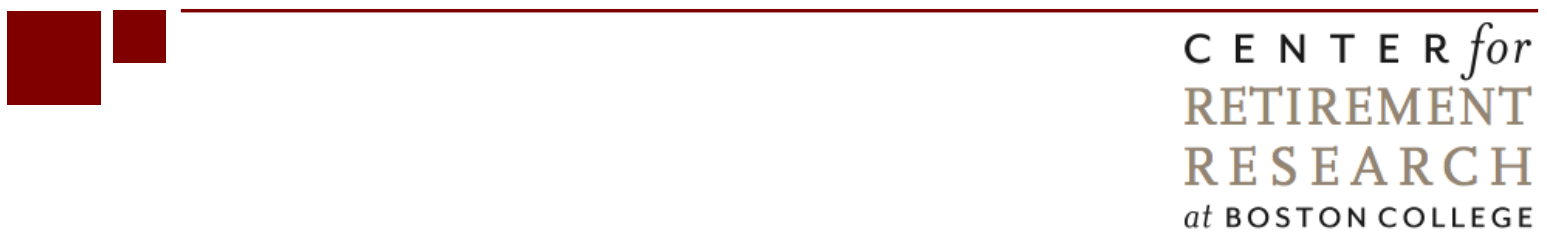

\title{
SPOUSAL LABOR MARKET EFFECTS FROM GOVERNMENT HEALTH INSURANCE: EVIDENCE FROM A VETERANS AFFAIRS EXPANSION
}

\author{
Melissa A. Boyle and Joanna N. Lahey \\ CRR WP 2012-16 \\ Date Submitted: April 2012 \\ Date Released: May 2012 \\ Center for Retirement Research at Boston College \\ Hovey House \\ 140 Commonwealth Avenue \\ Chestnut Hill, MA 02467 \\ Tel: 617-552-1762 Fax: 617-552-0191 \\ http://crr.bc.edu
}

Melissa A. Boyle is assistant professor of economics at the College of the Holy Cross. Joanna N. Lahey is an assistant professor of public policy at Texas A\&M University. The research reported here was performed pursuant to a grant from the U.S. Social Security Administration (SSA) funded as part of the Retirement Research Consortium (RRC). The opinions and conclusion expressed are solely those of the authors and do not represent the opinions or policy of SSA, any agency of the federal government, the RRC, the College of the Holy Cross, Texas A\&M University, or Boston College.

(C) 2012, by Melissa A. Boyle and Joanna N. Lahey. All rights reserved. Short sections of text, not to exceed two paragraphs, may be quoted without explicit permission provided that full credit, including (C) notice, is given to the source. 


\title{
About the Center for Retirement Research
}

The Center for Retirement Research at Boston College, part of a consortium that includes parallel centers at the University of Michigan and the National Bureau of Economic Research, was established in 1998 through a grant from the Social Security Administration. The Center's mission is to produce first-class research and forge a strong link between the academic community and decision-makers in the public and private sectors around an issue of critical importance to the nation's future. To achieve this mission, the Center sponsors a wide variety of research projects, transmits new findings to a broad audience, trains new scholars, and broadens access to valuable data sources.

\author{
Center for Retirement Research at Boston College \\ Hovey House \\ 140 Commonwealth Avenue \\ Chestnut Hill, MA 02467 \\ phone: 617-552-1762; fax: 617-552-0191 \\ e-mail: crr@bc.edu \\ crr.bc.edu
}

Affiliated Institutions:

The Brookings Institution

Massachusetts Institute of Technology

Syracuse University

Urban Institute 


\begin{abstract}
Although government expansion of health insurance to older workers leads to labor supply reductions for recipients, there may be spillover effects on the labor supply of affected spouses who are not covered by the programs. In the simplest model, health insurance on the job is paid for in terms of lower compensation on the job. Receiving health insurance exogenous to employment is akin to a positive income shock for the household, causing total household labor supply to drop. However, it is not clear within the household whether this decrease in labor supply will be borne by both spouses or by a specific spouse. We use a mid-1990s expansion of health insurance for U.S. veterans to provide evidence on the effects of expanding health insurance availability on the labor supply of spouses. Using data from the Current Population Survey, we employ a difference-in-differences strategy to compare the labor market behavior of the wives of older male veterans and non-veterans before and after the VA health benefits expansion to test the impact of public health insurance on these spouses. Our findings suggest that although household labor supply may decrease because of the income effect, the more flexible labor supply of wives allows the wife's labor supply to increase, particularly for those with lower education levels.
\end{abstract}




\section{Introduction}

As access to public health insurance increases, it is important to consider the impact of publicly-provided care on household labor. For workers approaching the age of retirement, it is particularly important to consider how public insurance expansions will alter the retirement and work decisions of the household. From previous work (Boyle and Lahey 2010), we know that for men between the ages of 55 and 64, the probability of leaving the labor force increases 3.33\% upon receipt of government-provided health insurance. However, although government expansion of health insurance to older workers decreases labor supply for those workers, there may be positive or negative spillover effects on the labor supply of affected spouses who are not covered by the programs.

The effect of publicly-provided healthcare receipt on a spouse's labor supply is not theoretically clear cut. There are several factors that are important to consider. In theory, household labor supply should decrease with the effective income shock from publicly-provided health insurance, but that labor supply reduction may not be borne equally by all members of the household. Because older wives generally have more flexible work options than their husbands, they may increase their work hours or enter the labor force part time once their husbands drop out of the labor force. If a husband's job has provided health insurance for his wife and he is offered public health insurance for himself, it may make sense for the wife to seek or retain employment options that allow her to acquire her own employer-provided insurance, such as by increasing her hours to full-time or obtaining a new job with health insurance coverage.

On the other hand, husbands and wives may make joint retirement decisions, which would increase the attractiveness of reducing hours for wives. Empirically, husbands and wives who both work often time their retirements close together (e.g. Blau 1998, Coile 2004; Hurd 1990). Most work studying joint retirement decisions has focused on monetary shocks such as pension or social security rule changes and benefits that are fungible across spouses; that is, from the perspective of the family unit, it does not matter which spouse gains the additional money. Both structural and empirical results in this literature are consistent with the hypothesis of complementarities of spousal leisure, although husbands seem more responsive to wives' monetary shocks than vice versa. In fact, Coile (2004) finds a very small effect of husband's financial incentives on wife's retirement. If women do not retire because they are less likely 
than their husbands to be able to obtain affordable health insurance once they do so, or because they value health insurance more than their spouses, then that may explain some of the mystery behind this asymmetry.

However, previous research that has examined the effect of health insurance receipt on spousal labor supply has generally found negative effects of husbands' health insurance availability on wives' labor supply (Abraham and Royalty 2006, Buchmueller and Valletta 1999, Kapinos 2009, Murasko 2008, Olson 1998). However, this research focuses on the effect of health insurance availability that can cover the entire family and not just the plan participant. The theoretical implications of this type of policy change, similar to extending COBRA or providing universal healthcare, are different than for a policy which only covers one specific member of the household. In these previously studied cases, the wife will have less of an incentive to increase labor supply (even when her husband previously provided the family's health insurance) because she will not need to provide health insurance for the family. Additionally, this literature tends to focus on younger age groups, who may be more attached to the labor force than those ages 55 and older. Some of this literature also has problems with positive marriage selection- "high quality” husbands are more likely to have both health insurance and "high quality" wives with their own labor force attachment. However, the main findings still hold even when this endogeneity is corrected for in more recent work (Kapinos 2009). A related literature finds that when SCHIP or Medicaid becomes available to children, women reduce their labor supply. However, this type of health insurance directly disincentivizes work through eligibility requirements (e.g. Montgomery and Navin 2000, Tomohara and Lee 2007, Winkler 1991, Yelowitz 1995).

In contrast, we examine the effect of a health benefits increase that is not linked to work and only covers the individual affected, not the entire family. We use a mid-1990s expansion of health insurance for U.S. veterans to provide evidence on the effects of expanding health insurance availability on the labor supply of wives of affected veterans. Using data from the Current Population Survey, we employ a difference-in-differences strategy to compare the labor market behavior of the wives of older veterans and non-veterans before and after the VA health benefits expansion to test the impact of public health insurance on these spouses. This experiment models the potential impact on women's labor supply if the husband reaches the age 
of Medicare eligibility earlier than his wife. Because wives in these cohorts are generally younger than their husbands, a husband's acquisition of VA coverage creates a situation analogous to a household in which the husband reaches the age of Medicare eligibility before his wife does.

Our findings suggest that although household labor supply may decrease because of the income effect, the more flexible labor supply of wives allows the wife's labor supply to increase. This effect appears to dominate the propensity for a wife to retire at the same time as her husband (which would imply a decrease in work on the extensive margin). This outcome is stronger for wives with high school education or less who are more likely than more educated women to seek occupations with flexible work hours. When husbands obtain health insurance independent of their jobs, wives with lower levels of education are more likely to enter the labor force. Although women with more education do not significantly increase their propensity to work on the extensive margin, they increase their earnings and hours worked, suggesting an increase on the intensive margin.

The organization of the paper is as follows. Section II describes the VA program. Section III gives a brief overview of the theoretical framework and the data. Section IV provides results. Section V discusses and concludes.

\section{Description of VA Program}

The Department of Veterans Affairs (VA) health care system was established in the 1930s to treat veterans with conditions resulting from their military service, and later, lowincome veterans. Prior to the time period we study, VA primarily provided inpatient care, and limited the availability of outpatient care for non-service-connected conditions to follow-up visits after an inpatient stay. ${ }^{1}$

The U.S. government began a major overhaul of this health care system in the mid-1990s. The impetus was an effort to catch up with progress in technology and efficiency in privatesector medicine. During this time, VA health care restructured to become a comprehensive health care system that focused on primary care and preventive medicine rather than hospital-

\footnotetext{
${ }^{1}$ For additional detail on VA health care and the associated reforms, see Boyle (2009).
} 
based specialty services. Following this change, VA experienced a 44 percent decline in the number of inpatients and a 66 percent increase in the total number of outpatient visits (Klein and Stockford 2001). At the same time, VA also changed its resource allocation system by distributing its health care budget using a capitated, patient-based formula, similar to the HMO model. $^{2}$ VA expected that these changes would result in significant cost reductions. Based on this assumption, it relaxed its rules on eligibility for care and offered services to all veterans rather than limiting guaranteed access to low-income and service-connected disabled veterans (GAO 1999).

Veterans were required to fill out paperwork enrolling in the VA program before they could use health care services. However, it is important to note that veterans could enroll without utilizing VA health care, but enrollment guaranteed the ability to use VA services in the future. Additionally, during the time period of our study, not enrolling did not imply that veterans would not be able to fill out paperwork and enroll in the future should they need VA services. In that respect, VA functioned as insurance for veterans even in the absence of enrollment, similar to the way that COBRA serves as insurance for the first 60 days after job separation regardless of whether the job leaver chooses to pay a premium. Nevertheless, 6.6 million veterans had enrolled by 2002 and VA's patient load had increased from 2.6 million veterans in 1995 to 4.3 million in 2002 (GAO 1996, GAO 2003). ${ }^{3}$

During our study period, enrolled veterans were sorted into one of seven priority groups. Those with service-related conditions resulting in disability of 50 percent or higher were considered the highest priority for treatment and were placed in group one. Those with incomes above VA determined thresholds and no service-connected disabilities were considered the lowest priority and placed in group seven. Priority groups 1-6 consisted of previously-eligible veterans and care remained free for them. Group 7 veterans were newly-eligible and were charged modest copayments. ${ }^{4}$ The priority groups were used only for enrollment purposes and

\footnotetext{
${ }^{2}$ In a capitated payment system, the health care provider is reimbursed a flat dollar amount for each patient regardless of the services provided.

${ }^{3}$ Prior to the reorganization, there was no formal enrollment system, so we cannot examine changes in enrollment, only changes in users.

${ }^{4}$ The copay was $\$ 2$ for each prescription for a 30-day supply in 2001 and $\$ 7$ in 2002. In 2002, copays for outpatient visits were $\$ 15$ for primary care, and $\$ 50$ for specialty care outpatient visits such as outpatient surgery, audiology and optometry and so on. Preventive care, including flu shots, hepatitis $C$ screenings, radiology services, electrocardiograms, and so on, was free. (Department of Veterans Affairs, 2002a)
} 
determination of copays during the time period of our study. For all enrollees, routine care appointments were provided on a first-come first-served basis regardless of group. ${ }^{5}$

The VA restructuring affected the availability of health care for all veterans. For those not previously eligible, the policy introduced a form of non-employer-provided health insurance. For the previously-eligible (i.e., low-income or disabled), it represented an increase in the scope of health care and health insurance, similar to what is available in the private sector. Therefore, this change provides an exogenous introduction of an outside health insurance option for all U.S. veterans but not for non-veterans. In order to estimate the spillover effect from publicly provided health insurance on spousal labor supply choices we compare the labor supply outcomes of wives of veterans to those of non-veterans before and after the change.

Previous research indicates that veterans used this health insurance to leave full-time employment. Between 35 and 70 percent of new VA health care users are individuals who drop private health insurance plans, potentially because they are leaving full-time work (Boyle 2009). In response to the policy change, Boyle and Lahey (2010) find a 3.3\% increase in the probability that a veteran leaves the labor force and an $8.4 \%$ decrease in the probability that a veteran works full time although some disadvantaged groups appear to increase their labor supply.

\section{Theory, Data, and Empirics}

Theory. In the simplest model, health insurance on the job is paid for in terms of lower compensation on the job. Receiving health insurance exogenous to employment is therefore akin to a positive income shock for the household. In this model, there is an income effect which dictates that household labor supply will drop.

However, it is not clear within the household whether this decrease in labor supply will be borne by both spouses or by a specific spouse. Boyle and Lahey (2010) find that husbands' labor supply drops upon receipt of public health insurance, but they do not explore the spillover effects on spousal labor supply. Because wives in these cohorts are more likely than their

\footnotetext{
${ }^{5}$ The priority groups did not receive differential access to care during the years of our study. However, in 2003, budget pressures caused the VA to deny care to the lowest-priority group - non-disabled non-poor veterans not previously enrolled in the system).
} 
husbands to have jobs with flexible hours, it is possible that a wife's hours may rise when a husband leaves a traditional 40-50 hour a week job, although the income effect would dictate that total family labor supply would decrease. If a woman had been receiving health insurance through her husband's job but he has been offered public health insurance, it may make sense for the wife to seek employment options that enable her to obtain her own employer-provided insurance, such as by increasing her hours to full-time or obtaining a new job with health insurance coverage. Alternatively, she might increase her work hours or seek a higher-paying position in order to pay for her own health insurance out-of-pocket. Therefore, we would expect to see a larger positive effect on labor market outcomes for women who did not have employerprovided health insurance of their own in the previous year.

On the other hand, because retirement is often a joint decision, we might also expect a woman's labor force participation to decrease when her husband's decreases. Because of potential complementarity of spousal leisure, the value of the wife's leisure time may increase when her husband retires. ${ }^{6}$ Therefore a husband's receipt of insurance would correspond to decreased work outcomes for the wife as well.

Results may also vary by education because of the different opportunities that are available for women of differing education levels. For example, women with less education may be better able than more educated women to control their job hours on the intensive margin, adding more hours to a part-time job. Women with more education may be more likely to retain or obtain full-time employment.

Data. This study uses data for the years 1992 through 2002 from the Census Bureau's March Current Population Survey (CPS). The CPS includes consistent information on employment and demographic controls, including veteran status, at an annual level for these years. Using a difference-in-differences (DD) estimation strategy, we compare the labor supply choices of wives of veterans and wives of non-veterans before and after the restructuring of VA health care. We thus limit our sample to married couples. Because we are mimicking the effects of a public insurance expansion for those approaching the current age of Medicare eligibility, we focus on individuals approaching retirement by limiting the sample to individuals ages 55

\footnotetext{
${ }^{6}$ See Coile 2004 for a discussion of this with respect to Social Security and private pension receipt.
} 
through $64 .^{7}$ Additionally, because of the small number of female veterans in this age cohort we restrict our veteran sample to include only males. We delete from our sample couples for which the wife is a veteran, as these wives will be directly affected by the treatment. ${ }^{8}$ With these restrictions, the treated population is therefore the wives of married male veterans ages 55 to 64, and the control group is the wives of married male non-veterans in the same age group. We define 1992-1995 as the pre-policy period and 1998-2002 as the post-policy period because changes in the VA health care were rolled out during 1996 and $1997 .{ }^{9}$

The CPS allows us to study labor market outcomes on the extensive margin such as labor force or employment exit, and on the intensive margin, such as hours worked, or movement into part-time work. It further allows us to examine earnings, although the universe for which we can study current earnings outcomes is limited during this time period, and type of labor force participation, such as self-employment. We are also able to examine the effects for different demographic groups, such as by education. ${ }^{10}$

Main Specification. We use a probit model to estimate the following equation:

$$
\mathrm{y}_{\mathrm{i}}=\beta_{0}+\beta_{1} \text { veteran }+\beta_{2} \text { veteran } * \text { post }+\mathbf{X}^{\prime} \beta_{3}+\delta_{\mathrm{t}}+\sigma_{\mathrm{s}}+\zeta_{\mathrm{st}}+\varepsilon
$$

The various dependent variables, $y_{i}$, include indicators for wives' labor supply outcomes including not working, self-employed, working part-time conditional on working, hours worked last week, weekly hours worked conditional on working any hours, weekly earnings, and

\footnotetext{
${ }^{7}$ Medicare eligibility at age 65 affects the impact of other public health insurance on the work decision, so we do not include those ages. In general, we find that the significance of results is slightly stronger if we limit to those age 50-64 rather than 55-64, possibly because of a larger sample size.

${ }^{8}$ We also delete the two observations for which the wife is under the age of 18 . The results are nearly identical when these are not deleted. We have also run regressions limiting wife ages to 45-64, 50-64, and 55-64. In general these results are qualitatively the same as our main results. Quantitatively, Table 3 results on work outcomes are slightly larger in magnitude and significance for these subsets (Table 7, Panel I provides some results) and Table 4 results are quantitatively similar.

${ }^{9}$ We end our study period in 2002 because VA revised the rules for obtaining health care January 2003. We have also estimated our regressions restricting our post-period to 1998-2001 because of a concern that particular Vietnam Era veterans are affected by a 2002 change that categorized diabetes as a war-related injury for veterans who may have been exposed to Agent Orange (Duggan et al. 2010, Autor and Duggan 2007). Results are qualitatively almost identical and significance increases in some regressions when we remove 2002 from our sample. Table 7, Panel III provides these results.

${ }^{10}$ Results by VA means-tested status are very similar to those by education level and are therefore not included.
} 
$\ln$ (weekly earnings). ${ }^{11}$ The variable not working is 0 if the wife is employed and 1 otherwise. The part-time variable reported is coded as 1 if the number of weekly hours worked is between 0 and 35 hours, and 0 if the individual works more than 35 hours. Self-employed is an indicator that is equal to 1 if the class of worker is self-employed (either incorporated or not incorporated) and 0 otherwise.

Among the independent variables, veteran is a dummy equal to 1 if the husband has been honorably discharged from active military duty, post is a dummy equal to 1 in the post-policy period, $\boldsymbol{X}$ is a vector of the wife's individual characteristics including age, race, education, and indicators for employer-provided health insurance and pensions in the previous or current year (including codes of 0 for those not employed) and $\delta_{t}$ is a full set of year dummies while $\sigma_{\mathrm{s}}$ is a full set of state dummies and $\zeta_{\text {st }}$ is a state-specific time trend. State dummies and year dummies account for heterogeneity in veteran take-up by state and time; this heterogeneity could be caused by local economic conditions making the program more attractive or variation in the degree to which the program was publicized to veterans in different regions. A state-specific time trend accounts for factors varying within states linearly over time in some specifications. Because the propensity for separating from the labor force will vary with benefits offered, we include indicators for employer-provided health insurance coverage and inclusion in a pension plan in the previous year in some specifications. Standard errors are adjusted for nonindependence of the errors within the veteran*year group.

Identification assumptions. In a difference-in-differences model, in order to interpret the results causally, specific assumptions must be satisfied. In our quasi-experimental setup, it must be true that: (1) wives of veterans and non-veterans are reasonably similar before the healthcare expansion, (2) only veterans are affected by the VA expansion, (3) no other shocks occur during this time period that differentially affect household labor supply choices, and (4) that the two

\footnotetext{
${ }^{11}$ Weekly earnings are earnings during a usual work week. This question is limited only to respondents in their fourth and eighth months of the survey, greatly reducing sample size. For the weekly earnings outcomes we code respondents in these months who did not have positive earnings as having zero earnings. Hourly earnings are constructed from weekly earnings and are available from the authors. We present weekly earnings because the results for hourly wages are similar to those for weekly earnings but, as a created variable, introduce more measurement error, and it is more problematic dealing with top-coding. Direct hourly earnings are available only for the subset of the sample that earns an hourly wage.
} 
populations would not trend differentially in the absence of a policy change due to unobservable factors.

Table 1 presents summary statistics demonstrating that the veteran and non-veteran samples are reasonably comparable in the pre-period. The average veteran is more educated, and slightly more likely to have employer-provided health insurance than the average non-veteran. As would be expected with assortative mating, wives of veterans are also somewhat more educated than wives of non-veterans. Because wives of veterans are slightly older than wives of non-veterans in the pre-period, and the age composition of veterans compared to non-veterans is changing over time, it is important to include controls for wife's age in all specifications. Wives of veterans are more likely to be not working than those of non-veterans in the pre-period sample. National Health Interview Survey calculations available in Boyle and Lahey (2010) demonstrate that there are no differences in health between veterans and non-veterans in the preperiod for the cohorts examined in this study.

Assumption (2) is valid because non-veterans and their spouses were not affected by the VA insurance expansion. Although some veterans already had access to VA health insurance, it was much less comprehensive than the coverage post-expansion, so those individuals are still substantially impacted by the change. Using textbook definitions of insurance, veterans were insured once VA coverage was offered (whether or not they formally enrolled) because they could sign up at any time if coverage was needed. Therefore even if they were not formally insured, they were insured in an economic sense, and thus were treated in the first stage. However, if some veterans were unaware of the insurance, our results will provide an underestimate of the behavioral effect of full government coverage. ${ }^{12}$

The third assumption would be violated if something else besides this expansion affects veterans and non-veterans or their wives differentially. Policy changes in 1996-1997 such as welfare reform are unlikely to affect older male veterans and their wives differently than older male non-veterans and their wives. Finally, unobserved systematic differences between the treatment and control groups could cause the treatment and control to trend differently in the post-period. However, we find no evidence of pre-existing trends using pre-policy years as a

\footnotetext{
${ }^{12}$ According to a 2001 survey, 22\% of unenrolled veterans said they were unaware of the program (Department of Veterans Affairs, 2002b).
} 
falsification exercise. Additionally, results are very similar when the model is fully interacted with veteran.

\section{Results}

First, we demonstrate that the VA expansion had a direct negative effect on the labor supply of married men. Table 2, Panel I provides the effects from estimating equation (1) on outcomes for married men only using the men's characteristics as controls. ${ }^{13}$ Veterans are more likely than the control group to be not working after receiving VA health insurance, with a significant coefficient of 0.008 points once a full set of controls is added, a 2.3\% increase relative to the pre-period veteran average of 0.35 . Veterans also increase part-time work with significant coefficients of 0.015 points in both specifications, an increase of $15.5 \%$ relative to the pre-period value of 0.097. Table 2, Panel II, provides a robustness check for these results, demonstrating that there is not a pre-trend by cutting the universe to only include pre-period data and creating a "fake post" variable that is 1 for 1994-1995 and 0 for 1992-1993. As would be expected if there was not a pre-trend, results are not significant, and indeed, are opposite-signed for the not working outcome.

Having demonstrated that the VA expansion decreased married men's labor supply, we turn to the spillover effects of this coverage on their wives who are not eligible to use VA health care. First, we test the effects of public insurance on wives' labor supply on the extensive margin. As shown in Table 3, Panel I, columns (1) and (2), we find that wives are between 1 and 2 ppt less likely to be not working once their husbands receive VA insurance. This implies a 3$4 \%$ increase in the probability of working relative to the pre-period average of 0.473 , although once full controls are added this effect is only marginally significant. These results appear to be driven by wives with high school or less education, as demonstrated in Table 3, Panel II, columns (1) and (2). Women with high school education or less are 3 ppt more likely (a 5.6\% increase off a base of 0.53) to work when their husbands are offered VA insurance. Coefficients are smaller, insignificant, and change signs when full controls are added, for women with at least

\footnotetext{
${ }^{13}$ These results differ slightly from those in Boyle and Lahey (2010) because the universe for that exercise included single men (who are shown to be more likely to leave the labor market than married men after receiving health insurance) and, in order to be consistent with the previous job-lock literature, limited to men who were working in the previous year. We do not condition on previous employment to examine the spillover effects on spouses. Additionally, in Boyle and Lahey (2010) we included industry and occupation controls in the set of full controls, but in our regressions with wife outcomes, the small size of some of these cells causes observations to drop out in the probit specifications, potentially resulting in selection biases. Results are nearly identical for the men and qualitatively similar for the women results with these controls included.
} 
some college education as shown in Tables 3, Panel III, columns (1) and (2). Similarly, we find in Table 3, Panel I, columns (3) and (4) that average hours worked per week for all women increases by approximately half an hour (between 0.44 and 0.63 hours). When hours worked are examined by women's education level, women with a high school education or less in Table 3, Panel II, columns (3) and (4), work 0.6 to 0.8 hours more per week when their husbands are offered health insurance, while results in Table 3, Panel III, columns (3) and (4) are positive but insignificant for those with more education. We proxy for work on the intensive margin with weekly hours worked and weekly earnings conditional on working any hours or having non-zero earnings respectively However, conditional on working any hours, hours worked do not increase significantly and the magnitudes are smaller, suggesting that the increase is primarily on the extensive margin.

In Table 4 we examine the effect on women's weekly wages. ${ }^{14}$ We construct this measure by dividing the annual income in the previous year by weeks worked in the previous year. As might be expected given the effects on work, weekly earnings increase for wives with high school or less education, with an increase between $\$ 13.43$ and $\$ 15.98$, as shown in the first two columns of Panel II. Results are still positive, but smaller and only significant in the minimum controls condition for wives with some college or more and for all wives. Log weekly earnings in Table 4, Panel I, columns (3) and (4) increase 3\% to 4\% for all women. Panel II, columns (3) and (4) show a 6\% to 7\% increase in weekly income for less educated wives, while no effect on $\ln$ (earnings) is shown for more educated wives. In results not shown, annual earnings in the previous year follow a similar pattern with less educated women earning \$546$\$ 719$ more per year on average. Hourly wages, created by dividing weekly wages by usual hours worked, do not yield significant results, except for ln(hourly wages) for women with high school or less education which find a $2-4 \%$ increase. These results taken as a whole suggest that wage movements are primarily occurring on the extensive margin. However, these results are also consistent with increased measurement error introduced by greater levels of variable construction.

Women who had health insurance coverage from their employers prior to the policy implementation may be more likely to stay employed than those who did not in order to keep

\footnotetext{
${ }^{14}$ Results trimming the top $5 \%$ of wages in an OLS regression framework are very similar.
} 
that coverage. However, women who did not have their own health insurance coverage may need to earn more money to self-insure if they lose their husbands' coverage, or may seek jobs with employer-provided insurance. Results in Table 5 Panel I demonstrate that women with health insurance in the previous year are $2.2 \mathrm{ppt}$ less likely to be not working, a $4.6 \%$ decrease off the base of 0.47 , but 1.8 ppt more likely to work part-time when their husbands get health insurance, a $6.4 \%$ increase off the base of 0.28 for all wives of veterans in the pre-period, and a $4 \%$ increase off the base of 0.43 for wives with prior health insurance. Women without health insurance in the previous year are less likely to be not working, but not significantly so and are 4.9 ppt less likely to be part-time a $12 \%$ decrease off the base of 0.40 for wives without health insurance in the previous period. As shown in Table 5, Panel II, for women with employerprovided health insurance, hours do not change significantly overall but decrease significantly conditional on working at all with a coefficient of -0.59 . For women without their own health insurance in the previous year, hours increase significantly overall, with a coefficient of 0.71 , and increase conditional on working any hours with a coefficient of 0.96. Earnings increase significantly for women without employer-provided health insurance both conditional on having any earnings and unconditional, but are not significant for women with health insurance. These results suggest that women with health insurance are more likely to stay employed but are not as focused on additional earnings, whereas women without health insurance increase their hours and earnings, possibly to afford health costs. ${ }^{15}$

We also look at the transitions that these wives make as a result of the change in their husbands' health insurance availability. Table 6 reports marginal effects from multinomial logit regressions that examine transitions into and out of not working, full- and part-time work and self-employment. Panel I replicates our main regression in a multinomial logit framework for all wives in our sample (i.e. not conditioning on the wife's labor force experiences in the previous year). Consistent with the main results, not working outcomes decrease about $1.95 \mathrm{ppt}$, and much of this decrease appears to be women increasing their full-time labor force participation. However, these transitions are different for women who were unattached to the labor force in the previous period. Panel II limits our sample to women who were not working at all in the previous year. These individuals are $0.61 \mathrm{ppt}$ more likely to enter the labor force upon the

\footnotetext{
${ }^{15}$ These results should be interpreted with some degree of caution, as the Current Population Survey variables for health insurance may not be reliable or consistent during these years (Fronstin 2000, Nelson and Mills 2001).
} 
husbands' receipt of VA insurance, and they appear to predominately enter part-time work for an employer $(0.37 \mathrm{ppt})$ or self-employment $(0.34 \mathrm{ppt})$. Women who worked part-time in the previous year, on the other hand, as shown in Panel III, do not change their labor force attachment, but instead work more hours, moving from part-time work into full-time work, with a decrease from part time work of $3.19 \mathrm{ppt}$ and an increase in full-time work of $3.88 \mathrm{ppt}$. This transition potentially makes them eligible for employer-provided health insurance or provides the additional income needed to self-insure. Finally, in Panel IV, we see no effect on women who were working full-time in the previous year. They neither leave the labor market nor change their labor force participation. These results as a whole are highly consistent with the hypotheses that married women value health insurance and seek out their own employer-provided health insurance or seek greater income in order to pay for potential medical expenses once their husbands are offered publicly provided health insurance.

Table 7 provides various robustness checks. In our base specification, we included all wives over the age of 18 in our sample. However, women of younger ages may have different labor market attachment than older women. Panel I provides results limiting to middle-aged and older wives. When wife ages are limited to 45-64, the percentage point magnitude of the results for not working and hours worked outcomes is very similar to that in the main specification in Table 3. Limiting women to the same ages as the men in the sample, age 55-64 provides larger magnitude results than our earlier sample. In this case, women decrease not working by $3.4 \mathrm{ppt}$ and increase hours worked by 1.12, about twice the magnitude as our base regression.

In Panel II of Table 7, we explore outcomes for wives whose husbands are working part time or are not working. Our main results in Table 3 include all wives regardless of their husbands' labor force attachment because the timing of labor supply changes within couples may vary upon the husbands' public insurance receipt. Some husbands with employer-provided insurance may continue full-time work in spite of the availability of VA insurance, with the expectation that they will reduce their labor supply once their wives are able to find an alternate source of insurance (i.e the wife might change her labor supply before or at the same time as the husband). Nevertheless, we may expect to see stronger results for couples in which the husband is either not working full-time or is not working at all, as these are couples for whom the offer is more likely to have had a direct effect (i.e. for whom the VA coverage potentially caused a 
decrease in the husband's labor supply). Panel II does demonstrate results with larger magnitudes for these two groups. Wives of husbands who are not working full time are more likely to work and work about 1.37 more hours per week after public health insurance is offered to their husbands. Similarly, wives of husbands who are not working at all are even more likely to work (decrease of not working of $4.3 \mathrm{ppt}$ ) and increase their hours worked by 1.76 hours per week.

Panel III provides additional robustness checks. Columns (1) and (2) demonstrate that fully interacting the independent variables in the model with veteran provides results similar to the base regression. Columns (3) and (4) demonstrate the same for removing the year 2002 (when diabetic Vietnam veterans potentially exposed to Agent Orange were re-categorized as having work-related injuries).

\section{Discussion and Conclusion}

In conclusion, when an older husband obtains public health insurance that does not cover his family members, less-educated wives increase their labor supply. Wives with a high school education or less increase their labor supply 3 percentage points, a 6\% increase. These less educated women also work 0.6-0.8 more hours per week after the policy change. We find no statistically significant change in probability of work for wives with higher levels of education. Weekly earnings increase for wives with high school education or less.

Results also differ by access to employer-provided health insurance in the previous year. Women without this health insurance increase their hours to a greater extent than women with this insurance in the previous year once their husbands are offered health insurance. Although all women on average increase their full-time work and their labor force participation, women who were not working in the previous year are more likely to enter the labor force to participate in part-time work or self-employment. Women who worked part-time in the previous year are more likely to increase their hours to full-time work. Women who previously worked full-time do not seem to be as affected by their husband's access to publicly provided health insurance. These results suggest that women in "career" jobs either cannot or will not adjust their own work behavior compared to women in more flexible employment. 
Our results are robust to several different specifications, including different choices of age, different year universes, and a full-veteran interaction. In addition, results seem to be stronger for women whose husbands are not working full-time or are not working at all.

We hypothesize that these changes occur because, as found in Boyle and Lahey (2010), when older men obtain health insurance not linked to their employment, they are more likely to leave the full-time for-an-employer labor force, and are thus less likely to be able to provide employer-based insurance to their families. In addition, older men in career jobs are more likely to have a choice between working full-time or not working, whereas women of the same cohort are more likely to be able to provide income from more flexible employment. Thus, in order to reach a target income or to provide family health insurance or to self-insure medical expenses, women with a high school education or less increase their labor supply. This effect comes from both women with less education increasing their labor force participation and from these women being less likely to leave the labor force. We do not find any evidence of work reductions based on complementarity of spousal leisure.

These results differ from the results on retiree health insurance or COBRA, which found a joint retirement effect for these insurances. However, the policy change is also different than that of coverage that includes the entire family rather than just a spouse. Women, who are on average not yet eligible for Medicare when their spouses become eligible (because men are, on average, older than their wives), will likely need to continue working in order to be able to cover the costs for their own health insurance or health care even after the spouse has retired. This need will be especially true for less-educated women, who are less likely to have access to employer-based retiree coverage of their own.

This research suggests that although men's labor force participation would decrease as an effect of increased public health insurance coverage, some of this decrease in participation would be made up for by an increase in the labor force participation and hours worked of their wives. 


\section{References}

Abraham, Jean, and Anne Beeson Royalty. 2006. "Health Insurance and Labor Market Outcomes: Joint Decision-Making within Households." Journal of Public Economics 90: 1561-1577.

Autor, David H. and Mark G. Duggan. 2007. "Distinguishing Income from Substitution Effects in Disability Insurance." American Economic Review 97(2): 119-24.

Blau, David. 1998. “Labor force dynamics of older married couples”. Journal of Labor Economics. 16(3): 595-629.

Boyle, Melissa. 2009. "Health and Utilization Effects of Increased Access to Publicly Provided Health Care: Evidence from the U.S. Department of Veterans Affairs.” Holy Cross Working Paper No. 09-02.

Boyle, Melissa and Joanna Lahey. 2010. "Health Insurance and the Labor Supply Decisions of Older Workers: Evidence from U.S. Department of Veterans Affairs Expansion.” Journal of Public Economics 94(7-8): 467-478.

Buchmueller, Thomas C. and Robert G. Valletta. 1999. "The Effect of Health Insurance on Married Female Labor Supply." Journal of Human Resources 34(1): 42-70.

Coile, Courtney. 2004. "Retirement Incentives and Couples' Retirement Decisions." Topics in Economic Analysis and Policy 4(1) Article 17: 1-28.

Department of Veterans Affairs. 2002a. Fact Sheet: VA Health Care and the Medical Benefits Package. http://www.hillsboroughcounty.org/veteransaffairs/resources/publications/healthcare.pdf

Department of Veterans Affairs. 2002b. 2001 National Survey of Veterans: Final Report. http://www1.va.gov/vetdata/docs/survey_final.htm.

Duggan, Mark G., Robert Rosenheck, and Perry Singleton. 2010. "Federal Policy and the Rise in Disability Enrollment: Evidence for the VA’s Disability Compensation Program.” Journal of Law and Economics 53(2): 379-398.

Fronstin, Paul, 2000. "Sources of Health Insurance and Characteristics of the Uninsured: Analysis of the March 2000 Current Population Survey.” Employee Benefit Research Institute Issue Brief No. 228.

Hurd, Michael D. 1990. “The Joint Retirement Decision of Husbands and Wives.” In Issues in the Economics of Aging ed. David Wise. p231-258.

Kapinos, Kandice A. 2009. "Changes in Spousal Health Insurance Coverage and Female Labor Supply Decisions." Forum of Health Economics and Policy 12(2): Article 1. 
Klein, Robert E. and Donald D. Stockford. 2001. Data on the Socioeconomic Status of Veterans and on VA Program Usage.

www1.va.gov/VETDATA/docs/SpecialReports/sesprogramnet5-31-01.ppt

Montgomery, Edward and John C. Navin. 2000. "Cross-State Variation in Medicaid Programs and Female Labor Supply.” Economic Inquiry 38(3): 402-418.

Murasko, Jason E. 2008. "Married Women's Labor Supply and Spousal Health Insurance Coverage in the United States: Results from Panel Data." Journal of Family and Economic Issues 29(3): 391-406.

Nelson, Charles T. and Robert J. Mills. 2001. "The March CPS Health Insurance Verification Question and its Effect on Estimates of the Uninsured.” U.S. Census Bureau. http://www.census.gov/hhes/www/hlthins/publications/verification.html. Last Accessed $6 / 28 / 11$.

Olson, Craig A. 1998. "A Comparison of Parametric and Semiparametric Estimates of the Effect of Spousal Health Insurance Coverage on Weekly Hours Worked by Wives." Journal of Applied Econometrics_13(5): 543-65.

Tomohara, Akinori and Ho Jin Lee. 2007. “Did State Children’s Health Insurance Program Affect Married Women's Labor Supply? Journal of Family and Economic Issues 28(4): 668-683.

U.S. General Accounting Office. 1996. VA Health Care: Efforts to Improve Veterans' Access to Primary Care Services. GAO/T-HEHS-96-134. Washington, D.C.: U.S. Government Printing Office.

U.S. General Accounting Office. 1999. Veterans’ Affairs: Progress and Challenges in Transforming Health Care. GAO/T-HEHS-99-109. Washington, D.C: U.S. Government Printing Office.

U.S. General Accounting Office. 2003. VA Health Care: Framework for Analyzing Capital Asset Realignment for Enhanced Services Decisions. GAO-03-1103R. Washington, D.C.: U.S. Government Printing Office.

Winkler, Anne E. 1991. “The Incentive Effects of Medicaid on Women's Labor Supply.” The Journal of Human Resources 26(2): 308-337.

Yelowitz, Aaron S. 1995. "The Medicaid Notch, Labor Supply, and Welfare Participation: Evidence from Eligibility Expansions.” The Quarterly Journal of Economics 110(4): 909939. 
Table 1. Summary Statistics, CPS 1992-2002

\begin{tabular}{|c|c|c|c|c|}
\hline \multirow[b]{4}{*}{ Observations } & \multicolumn{2}{|c|}{ Veterans } & \multicolumn{2}{|c|}{ Non-Veterans } \\
\hline & Pre & Post & Pre & Post \\
\hline & \multicolumn{4}{|c|}{ Husbands } \\
\hline & 10,272 & 9,596 & 8,292 & 12,964 \\
\hline Age & 59.808 & 59.251 & 58.911 & 59.022 \\
\hline White & 0.943 & 0.924 & 0.867 & 0.867 \\
\hline No HS & 0.159 & 0.073 & 0.341 & 0.244 \\
\hline HS & 0.363 & 0.359 & 0.304 & 0.295 \\
\hline Some College & 0.227 & 0.281 & 0.137 & 0.165 \\
\hline College Grad & 0.148 & 0.162 & 0.105 & 0.147 \\
\hline Grad School & 0.102 & 0.125 & 0.114 & 0.150 \\
\hline Pension Plan & 0.403 & 0.451 & 0.371 & 0.397 \\
\hline Empl. HI Plan & 0.651 & 0.657 & 0.573 & 0.579 \\
\hline Northeast & 0.233 & 0.212 & 0.251 & 0.220 \\
\hline Midwest & 0.252 & 0.236 & 0.237 & 0.225 \\
\hline South & 0.308 & 0.315 & 0.308 & 0.322 \\
\hline West & 0.207 & 0.237 & 0.204 & 0.234 \\
\hline Not Working & 0.350 & 0.309 & 0.322 & 0.295 \\
\hline Self-Employed & 0.163 & 0.148 & 0.184 & 0.170 \\
\hline Hours Worked & 41.860 & 42.110 & 42.566 & 42.903 \\
\hline \multicolumn{5}{|l|}{ Occupations: } \\
\hline Prof/Management & 0.238 & 0.263 & 0.221 & 0.265 \\
\hline Tech/Sales/Cleric & 0.158 & 0.159 & 0.127 & 0.125 \\
\hline Service & 0.053 & 0.057 & 0.064 & 0.063 \\
\hline Farming & 0.037 & 0.026 & 0.056 & 0.045 \\
\hline Craftsman & 0.130 & 0.141 & 0.135 & 0.131 \\
\hline Operator & 0.125 & 0.121 & 0.154 & 0.142 \\
\hline \multicolumn{5}{|l|}{ Industries: } \\
\hline Agric/Mining & 0.040 & 0.029 & 0.056 & 0.048 \\
\hline Construction & 0.062 & 0.065 & 0.072 & 0.075 \\
\hline
\end{tabular}


Table 1. Summary Statistics, CPS 1992-2002 (cont'd)

\begin{tabular}{lllll} 
Manufacturing & 0.152 & 0.134 & 0.174 & 0.147 \\
Transport/Commun & 0.075 & 0.090 & 0.063 & 0.063 \\
Trade & 0.112 & 0.107 & 0.125 & 0.114 \\
Finance/Real estate & 0.044 & 0.046 & 0.036 & 0.043 \\
Business/Repair & 0.037 & 0.047 & 0.039 & 0.045 \\
Personal & 0.024 & 0.021 & 0.025 & 0.028 \\
Public & 0.047 & 0.055 & 0.027 & 0.029 \\
Professional & 0.113 & 0.123 & 0.116 & 0.141 \\
& Wives & & & \\
\cline { 2 - 5 } Observations & 10,187 & 9,493 & 8,164 & 12,674 \\
Age & 56.078 & 55.417 & 55.085 & 55.265 \\
White & 0.938 & 0.918 & 0.868 & 0.869 \\
No HS & 0.144 & 0.091 & 0.263 & 0.186 \\
HS & 0.468 & 0.416 & 0.412 & 0.369 \\
Some College & 0.230 & 0.274 & 0.175 & 0.215 \\
College Grad & 0.101 & 0.137 & 0.090 & 0.135 \\
Grad School & 0.053 & 0.078 & 0.054 & 0.086 \\
Not Working & 0.473 & 0.385 & 0.467 & 0.406 \\
Self-Employed & 0.083 & 0.082 & 0.090 & 0.088 \\
Hours Worked & 17.375 & 20.922 & 17.543 & 19.867 \\
\hline \hline
\end{tabular}

Note: Universe is limited to married couples with husbands between the ages of 55 and 64 whose wives are not veterans. Two observations with wives under the age of 18 have been deleted from the universe. The pre period includes year s 1992-1995 and the post period includes years 1998-2002. 
Table 2. Effect of Insurance Receipt on Labor Supply Outcomes for Veterans

\begin{tabular}{|c|c|c|}
\hline Not Working & Part Time & Self Employed \\
\hline (1) (2) & (3) & (5) \\
\hline
\end{tabular}

\begin{tabular}{|c|c|c|c|c|c|c|}
\hline \multirow[b]{2}{*}{ veteran*post } & \multicolumn{6}{|c|}{ Panel I: Effects of Insurance Receipt } \\
\hline & 0.0053 & $0.0077 *$ & $0.0153 * *$ & $0.0147 * *$ & -0.0017 & -0.0012 \\
\hline & $(0.0049)$ & $(0.0034)$ & $(0.0054)$ & $(0.0053)$ & $(0.0042)$ & $(0.0044)$ \\
\hline \multirow[t]{2}{*}{ veteran } & $0.0174 * *$ & $0.0321 * *$ & -0.0014 & 0.0042 & $-0.0350 * *$ & $-0.0241 * *$ \\
\hline & $(0.0037)$ & $(0.0027)$ & $(0.0041)$ & $(0.0040)$ & $(0.0039)$ & $(0.0044)$ \\
\hline \multirow[t]{2}{*}{ Observations } & 41,124 & 41,124 & 26,404 & 26,404 & 41,124 & 41,124 \\
\hline & \multicolumn{6}{|c|}{ Panel II: Falsification exercise: $1992-1993=$ pre, $1994-1995=$ post } \\
\hline \multirow[t]{2}{*}{ veteran*fakepost } & -0.0129 & -0.0051 & 0.0100 & 0.0068 & 0.0081 & 0.0056 \\
\hline & $(0.0079)$ & $(0.0047)$ & $(0.0083)$ & $(0.0072)$ & $(0.0071)$ & $(0.0085)$ \\
\hline \multirow[t]{2}{*}{ veteran } & $0.0258 * *$ & $0.0361 * *$ & $-0.0057+$ & 0.0014 & $-0.0387 * *$ & $-0.0267 * *$ \\
\hline & $(0.0070)$ & $(0.0044)$ & $(0.0034)$ & $(0.0039)$ & $(0.0049)$ & $(0.0060)$ \\
\hline Full controls? & No & Yes & No & Yes & No & Yes \\
\hline State time trend? & No & Yes & No & Yes & No & Yes \\
\hline Observations & 18,564 & 18,564 & 11,486 & 11,486 & 18,564 & 18,564 \\
\hline
\end{tabular}

Notes: Coefficient estimates are taken from a probit regression as described in eq. (1). Marginal effects are reported. Regressions include age, race, state, year and education dummies and a constant. Full controls include health insurance receipt in the previous year and pension in the previous year for columns (1) and (2) and current year in columns (3)-(4) and a state-specific time trend. The universe in Panel I includes the years $1992-2002$ with 1996 and 1997 omitted. The universe in Panel II includes years 1992-1995, with fakepost indicating the years 1994-1995. Men whose wives are veterans or under age 18 are removed from the universe. Robust standard errors in parentheses are clustered on veteran and year. 
Table 3. Effect of Husband's Insurance on Wife's outcomes

\begin{tabular}{|c|c|c|c|c|c|c|}
\hline & Not Working & & Hours Worked & & Hours worked & \\
\hline & Min Controls & Full Controls & Min Controls & Full Controls & Min Controls & Full Controls \\
\hline & (1) & (2) & (3) & (4) & (5) & (6) \\
\hline & I. All Wives & & & & & \\
\hline veteran*post & $-0.0180 *$ & $-0.0136+$ & $0.6336 * *$ & $0.4365+$ & 0.2207 & 0.2403 \\
\hline & $(0.0071)$ & $(0.0081)$ & $(0.2146)$ & $(0.2071)$ & $(0.2308)$ & $(0.2230)$ \\
\hline veteran & $0.0160 * *$ & $0.0243 * *$ & $-0.4422 * *$ & $-0.6665 * *$ & 0.0262 & -0.1534 \\
\hline & $(0.0045)$ & $(0.0046)$ & $(0.1186)$ & $(0.1295)$ & $(0.1616)$ & $(0.1626)$ \\
\hline Observations & 40,495 & 40,495 & 40,518 & 40,518 & 21,802 & 21,802 \\
\hline & II. Wives wit & gh School Educ & or Less Educatic & & & \\
\hline veteran*post & $-0.0302 * *$ & $-0.0298 * *$ & $0.7967 * *$ & $0.6303^{*}$ & -0.0251 & 0.0708 \\
\hline & $(0.0092)$ & $(0.0113)$ & $(0.2413)$ & $(0.2663)$ & $(0.1825)$ & $(0.1949)$ \\
\hline veteran & $0.0218^{* *}$ & $0.0330 * *$ & $-0.6943 * *$ & $-0.9350 * *$ & -0.0921 & -0.2837 \\
\hline & $(0.0072)$ & $(0.0088)$ & $(0.1620)$ & $(0.1841)$ & $(0.1403)$ & $(0.1735)$ \\
\hline Observations & 23,768 & 23,768 & 23,827 & 23,827 & 11,311 & 11,311 \\
\hline & III. Wives wit & me College or I & Education & & & \\
\hline veteran*post & -0.0035 & 0.0076 & 0.4789 & 0.1495 & 0.5698 & 0.4861 \\
\hline & $(0.0085)$ & $(0.0092)$ & $(0.5074)$ & $(0.4371)$ & $(0.5091)$ & $(0.5123)$ \\
\hline veteran & 0.0046 & $0.0086+$ & -0.2125 & -0.3957 & -0.2841 & -0.3889 \\
\hline & $(0.0057)$ & $(0.0050)$ & $(0.3385)$ & $(0.2740)$ & $(0.3856)$ & $(0.3982)$ \\
\hline
\end{tabular}


Table 3. Effect of Husband's Insurance on Wife's outcomes (cont'd)

Observations

13,837

13,837

13,881

13,881

8,464

8,464

Notes: Coefficient estimates are taken from equation (1). Columns (1) and (2) report the marginal effects from a probit regression. Columns (3)-(6) report OLS results. Regressions include age, race, state, year and education dummies and a constant. Full controls include pension and health insurance receipt in the previous year and a state-specific time trend. Robust standard errors in parentheses are clustered on veteran and year.

+ significant at $10 \% ; *$ significant at $5 \% ; * *$ significant at $1 \%$ 
Table 4. Effect of Husband's Insurance on Wife's Earnings

Earnings
Min Controls Full Controls

$\ln ($ Earnings)

$(1)$

(2)

\begin{tabular}{ll}
\hline Min Controls & Full Controls \\
\hline$(3)$ & (4)
\end{tabular}

\begin{tabular}{lllll}
\hline \multirow{2}{*}{ veteran*post } & I. All Wives & & & \\
\cline { 2 - 5 } & $7.6405^{*}$ & 3.8002 & $0.0404^{*}$ & $0.0308^{*}$ \\
\multirow{2}{*}{ veteran } & $(3.4699)$ & $(3.0635)$ & $(0.0144)$ & $(0.0128)$ \\
& 0.6558 & -1.4098 & 0.0147 & 0.0096 \\
\multirow{2}{*}{ Observations } & 35,600 & $(2.4975)$ & $(0.0138)$ & $(0.0127)$ \\
\hline
\end{tabular}

II. Wives with High School Education or Less Education

\begin{tabular}{lllll} 
veteran*post & $15.9870^{* *}$ & $13.4260^{* *}$ & $0.0670^{*}$ & $0.0547^{*}$ \\
\multirow{2}{*}{ veteran } & $(3.8044)$ & $(3.6204)$ & $(0.0234)$ & $(0.0189)$ \\
& 1.3220 & -2.7254 & -0.0006 & -0.0089 \\
& $(3.6550)$ & $(2.9863)$ & $(0.0212)$ & $(0.0178)$
\end{tabular}

Observations $\quad 20,318$

20,318

10,321

10,321

\begin{tabular}{lllll}
\hline \multirow{2}{*}{ veteran*post } & \multicolumn{4}{l}{ III. Wives with Some College or More Education } \\
\cline { 2 - 5 } & $9.0760^{* *}$ & 3.5498 & $0.0277+$ & -0.0009 \\
\multirow{2}{*}{ veteran } & $(1.5375)$ & $(2.4440)$ & $(0.0132)$ & $(0.0142)$ \\
& $-3.5812^{* *}$ & $-5.4468^{*}$ & 0.0163 & 0.0204 \\
\multirow{2}{*}{ Observations } & $(0.9357)$ & $(1.9335)$ & $(0.0122)$ & $(0.0122)$ \\
\hline \hline
\end{tabular}

Notes: Coefficient estimates report regression estimates of equation (1). Weekly earnings are created from previous year variables in 1982-1984 dollars using the BLS CPI inflator. Universe years are 1992-2001, omitting 1996 and 1997 (CPS years are 1993-2002). Regressions include age, race, state, year and education dummies and a constant. Full controls include pension and health insurance receipt in the previous year and a state-specific time trend. Robust standard errors in parentheses are clustered on veteran and year.

+ significant at $10 \%$; * significant at $5 \%$; ** significant at $1 \%$ 
Table 5. Results by Wife's Health Insurance Receipt

Wife Had Employer-Provided Health Insurance

$$
\text { (1) }
$$

\section{Panel I: Work outcomes}

veteran*post

Not Working

$-0.0216 * *$

(0.0062)

veteran

$0.0249 * *$

(0.0035)

Sig different?

Observations

veteran*post

veteran

Observations

Part Time

0.0181*

Panel II: Hours Outcomes

Wife Without Employer-Provided Health Insurance

(3) (4)

Not Working Part Time

$-0.0137-0.0486^{* *}$

(0.0092) (0.0147)

0.0143* $\quad 0.0141$

(0.0065) (0.0100)

Yes Yes

$26,339 \quad 10,693$

\begin{tabular}{lllll}
\hline Hrs Worked & Hrs Worked|hrs $>0$ & & Hrs Worked & Hrs Worked|hrs $>0$ \\
\cline { 1 - 1 }$(0.3765$ & $-0.5850^{*}$ & & $0.7112^{*}$ & $0.9644+$ \\
$(0.3853)$ & $(0.2279)$ & & $(0.2702)$ & $(0.4737)$ \\
$-0.5319+$ & $0.4188^{*}$ & & $-0.5303^{* *}$ & -0.4239 \\
$(0.2922)$ & $(0.1811)$ & $(0.1319)$ & $(0.3621)$ \\
& & Yes & Yes \\
14,129 & 11,083 & 26,389 & 10,719 \\
\hline
\end{tabular}


Table 5. Results by Wife's Health Insurance Receipt (cont'd)

Panel III: Earnings Outcomes

\begin{tabular}{|c|c|c|c|c|}
\hline & Earnings & $\ln$ (Earnings) & Earnings & $\ln ($ Earnings $)$ \\
\hline \multirow[t]{2}{*}{ veteran*post } & -2.2616 & -0.0185 & $10.9045^{* *}$ & $0.0907 * *$ \\
\hline & (8.0131) & $(0.0120)$ & (3.6759) & $(0.0203)$ \\
\hline \multirow[t]{2}{*}{ veteran } & 6.8185 & $0.0384 * *$ & -2.5457 & 0.0032 \\
\hline & (5.8639) & $(0.0083)$ & $(3.4074)$ & $(0.0154)$ \\
\hline Observations & 12,664 & 10,877 & 22,936 & 9,699 \\
\hline
\end{tabular}

* significant at $5 \%$; ** significant at $1 \%$.

Note: Coefficient estimates are taken from equation (1). Panel I reports the marginal effects from a probit regression. Panels II and II report results from an OLS regression. Earnings are in 1982-1984 dollars using the BLS CPI inflator. Regressions include race, and a full set of state, year, age, and education dummies and a constant. Robust standard errors in parentheses are clustered on veteran and year. 
Table 6. Pathways: Multinomial Logits

\begin{tabular}{|c|c|c|c|c|}
\hline & (1) & (2) & (3) & (4) \\
\hline & Full-Time & Part-Time & Self-Employed & Not Working \\
\hline & \multicolumn{4}{|c|}{ I. All Wives } \\
\hline \multirow[t]{2}{*}{ veteran*post } & $0.0184^{* *}$ & -0.0009 & 0.0020 & $-0.0195^{* *}$ \\
\hline & $(0.0069)$ & $(0.0036)$ & $(0.0040)$ & $(0.0068)$ \\
\hline \multirow[t]{2}{*}{ veteran } & -0.0003 & -0.0027 & $-0.0144 * *$ & $0.0174^{* *}$ \\
\hline & $(0.0042)$ & $(0.0033)$ & $(0.0030)$ & $(0.0046)$ \\
\hline \multirow[t]{2}{*}{ Observations } & 39,526 & 39,526 & 39,526 & 39,526 \\
\hline & \multicolumn{4}{|c|}{ II. Wives who Worked 0 Weeks Last Year } \\
\hline \multirow[t]{2}{*}{ veteran*post } & $-0.0009+$ & $0.0037^{*}$ & $0.0034^{*}$ & $-0.0061^{* *}$ \\
\hline & $(0.0005)$ & $(0.0017)$ & $(0.0014)$ & $(0.0022)$ \\
\hline \multirow[t]{2}{*}{ veteran } & -0.00002 & $-0.0026^{*}$ & $-0.0034 * *$ & $0.0061^{* *}$ \\
\hline & $(0.0006)$ & $(0.0011)$ & $(0.0007)$ & $(0.0015)$ \\
\hline \multirow[t]{2}{*}{ Observations } & 15,028 & 15,028 & 15,028 & 15,028 \\
\hline & \multicolumn{4}{|c|}{ III. Wives who Worked Part-Time Last Year } \\
\hline \multirow[t]{2}{*}{ veteran*post } & $0.0388^{*}$ & $-0.0319 *$ & -0.0074 & 0.0006 \\
\hline & $(0.0153)$ & $(0.0200)$ & $(0.0184)$ & $(0.0102)$ \\
\hline \multirow[t]{2}{*}{ veteran } & $-0.0369 * *$ & $0.0391 * *$ & -0.0066 & 0.0044 \\
\hline & (0.0045) & $(0.0070)$ & $(0.0172)$ & $(0.0097)$ \\
\hline Observations & 5,081 & 5,081 & 5,081 & 5,081 \\
\hline
\end{tabular}


Table 6. Pathways: Multinomial Logits (cont'd)

\begin{tabular}{lllll}
\multirow{4}{*}{ veteran*post } & \multicolumn{4}{l}{ IV. Wives who Worked Full-Time Last Year } \\
\cline { 2 - 5 } & -0.0060 & -0.0036 & 0.0057 & 0.0038 \\
\multirow{2}{*}{ veteran } & $(0.0046)$ & $(0.0028)$ & $(0.0038)$ & $(0.0038)$ \\
& $0.0244^{* *}$ & 0.0005 & $-0.0228^{* *}$ & -0.0022 \\
& $(0.0025)$ & $(0.0023)$ & $(0.0025)$ & $(0.0029)$ \\
Observations & 15,490 & 15,490 & 15,490 & 15,490 \\
\hline
\end{tabular}

Notes: Coefficient estimates are from a multinomial

logit. Regressions include age, race, state, year and education dummies and a constant. Part-time in the previous year is defined as working more than 0 and less than 35 hours/week and at least 40 weeks in the previous year. Full-time in the previous year is defined as 35 or more hours/week and at least 40 weeks in the previous year. Robust standard errors in parentheses are clustered on veteran and year.

+ significant at $10 \% ; *$ significant at $5 \% ; *$ significant at $1 \%$ 
Table 7. Robustness Checks

(1)

Not Working Hours Worked

Panel I: Different Wife Ages

\begin{tabular}{|c|c|c|c|c|}
\hline & Not Working & Hours Worked & Not Working & Hours Worked \\
\hline & \multicolumn{4}{|c|}{ Panel I: Different Wife Ages } \\
\hline & \multicolumn{2}{|l|}{ Ages 45-64 } & \multicolumn{2}{|l|}{ Ages 55-64 } \\
\hline \multirow[t]{2}{*}{ veteran*post } & $-0.0160 *$ & $0.7803^{* *}$ & $-0.0337 * *$ & $1.1243^{*}$ \\
\hline & $(0.0074)$ & $(0.2506)$ & $(0.0082)$ & $(0.4260)$ \\
\hline \multirow[t]{2}{*}{ veteran } & $0.0164 * *$ & $-0.5570 * *$ & $0.0310 * *$ & $-0.9898 *$ \\
\hline & $(0.0053)$ & $(0.1329)$ & $(0.0073)$ & $(0.3626)$ \\
\hline \multirow[t]{3}{*}{ Observations } & 36,762 & 36,762 & 23,314 & 23,314 \\
\hline & \multicolumn{4}{|c|}{ Panel II: Limiting Husbands } \\
\hline & \multicolumn{2}{|c|}{ Husband Not Working Full-Time } & \multicolumn{2}{|c|}{ Husband Not Working } \\
\hline \multirow[t]{2}{*}{ veteran*post } & $-0.0353 * *$ & $1.3721^{* *}$ & $-0.0430 * *$ & $1.7639 * *$ \\
\hline & $(0.0057)$ & $(0.2106)$ & $(0.0095)$ & $(0.2712)$ \\
\hline \multirow[t]{2}{*}{ veteran } & $0.0159 * *$ & $-0.3735 * *$ & 0.0055 & $-0.5967 * *$ \\
\hline & $(0.0048)$ & $(0.1142)$ & $(0.0080)$ & $(0.1939)$ \\
\hline Observations & 23,732 & 23,774 & 12,751 & 12,827 \\
\hline
\end{tabular}

(3)

(4)

Panel III: Additional Checks

Full veteran interaction No 2002

\begin{tabular}{llllll}
\cline { 2 - 3 } \cline { 5 - 6 } veteran*post & $-0.0200^{* *}$ & $0.6017^{*}$ & & $-0.0263^{* *}$ & $0.9216^{* *}$ \\
& $(0.0070)$ & $(0.2296)$ & & $(0.0059)$ & $(0.1562)$
\end{tabular}

veteran

--- - - -

$0.0155 * * \quad-0.4478 * *$

$(0.0046) \quad(0.1287)$

$\begin{array}{lllll}\text { Observations } & 40,477 & 40,518 & 34,537 & 34,587\end{array}$

Note: Coefficient estimates are taken from equation(1). Columns (1) and (3) report the marginal effects from a probit regression. The remaining columns report results from an OLS regression. Full veteran interactions do not show a veteran main effect because all controls are interacted with veteran. Regressions include race, and a full set of state, year, age, and education dummies and a constant. Robust standard errors in parentheses are clustered on veteran and year.

* significant at 5\%; ** significant at $1 \%$ 


\section{RECENT WORKING PAPERS FROM THE CENTER FOR RETIREMENT RESEARCH AT BOSTON COLLEGE}

Measuring Social Security Proposals by More than Solvency: Impacts on Poverty, Progressivity, Horizontal Equity, and Work Incentives

Melissa M. Favreault and C. Eugene Steuerle, April 2012

How Important Is Asset Allocation to Financial Security in Retirement?

Alicia H. Munnell, Natalia Sergeyevna Orlova, and Anthony Webb, April 2012

Great Recession-Induced Early Claimers: Who Are They? How Much Do They Lose?

Matthew S. Rutledge and Norma B. Coe, April 2012

Effects of Employer Health Costs on the Trend and Distribution of Social Security-Taxable Wages

Gary Burtless And Sveta Milusheva, April 2012

Should Households Base Asset Decumulation Strategies on Required Minimum

Distribution Tables?

Wei Sun and Anthony Webb, April 2012

Geographic Mobility Among Residents in Seniors Housing and Care Communities:

Evidence from the Residents Financial Survey

Norma B. Coe and April Yanyuan Wu, April 2012

Costs and Concerns among Residents in Seniors Housing and Care Communities: Evidence from the Residents Financial Survey

Norma B. Coe and April Yanyuan Wu, April 2012

Financial Well-Being of Residents in Seniors Housing and Care Communities: Evidence from the Residents Financial Survey

Norma B. Coe and April Yanyuan Wu, April 2012

Residents in Senior Housing and Care Communities: Overview of the Residents Financial Survey

Norma B. Coe and April Yanyuan Wu, April 2012

Social Security Claiming: Trends and Business Cycle Effects

Owen Haaga and Richard W. Johnson, February 2012

All working papers are available on the Center for Retirement Research website

(http://crr.bc.edu) and can be requested by e-mail (crr@bc.edu) or phone (617-552-1762). 